\title{
The Integration of the Pottery Handicraft Together with the Basketwork Handicraft Promoting Economic Community Strength
}

\author{
Panu Pattanapanithipong ${ }^{1} \&$ Rosjana Chandhasa ${ }^{2}$ \\ ${ }^{1}$ Faculty of Fine Arts, Department of Visual Art Design: Product Design, Srinakharinwirot University, Thailand \\ ${ }^{2}$ Faculty of Industrial Technology, Department of Industrial Design, Suan Sunandha Rajabhat University, \\ Thailand \\ Correspondence: Panu Pattanapanithipong. E-mail: panup@g.swu.ac.th
}

$\begin{array}{cc}\text { Received: March 19, } 2018 \quad \text { Accepted: April 20, } 2018 \quad \text { Online Published: May 28, } 2018 \\ \text { doi:10.5539/ass.v14n6p50 } & \text { URL: https://doi.org/10.5539/ass.v14n6p50 }\end{array}$

\begin{abstract}
A study of the integration of the pottery handicraft together with the basketwork promoting economic community strength aims to 1) to study the basketwork identity to apply with the pottery handicraft 2 ) to examine the experimental design and to develop the pottery handicraft product combined with the basketwork in order to beautiful identical according to market qualifications and 3) to evaluate the market testing of the handicraft product developed conduce to the guidelines for producers apply to use. The samples were 400 people who interested in handicraft wherewith purposive sampling at the handicraft shop by used the accidental sampling, inquired for collect the data before as well as after design, evaluated by 3 groups of community product producer as 3 stars level which experience 10 years at least and 3 product design experts in order to evaluate the optimal pattern of product modified, therefrom, created the prototype as well as evaluated the opinion comments of consumer towards product designs. The results revealed that the most wanted of consumer that were the lamp product, basket product and decorated item products, the container rim of the $3^{\text {rd }}$ pattern by weaving method was appropriate for forming pattern which were combined method with easy, strong and stable pattern, easy to fix when being ruined, the product pattern have been tested marketing by consumer found the satisfaction overall was the highest level, furthermore they satisfied in term of beauty than in term of usability.
\end{abstract}

Keywords: pottery, handicraft, basketwork, the integration, community

\section{Introduction}

Under the context of significant changes both global and domestic country, country development in the future is necessary to prepare and produce the country's immune system strong under the philosophy of sufficiency economy to be able adapt to accommodate the impact of the changes in the future with constantly. The conceptual framework of The Eleventh National Economic and Social Development based on the integrated development concept as a holistic with "people-centered development" there are connects to all dimensions of integrated development thought people, social, economic and environment by leading the nation's capital as the potential to integrated utilization and collaboration along with reinforce strengthen the country as the foundation for the important development country by enhancing human capital, social capital, cultural capital, using wisdom, science, technology as well as creativity conform to the need of domestic and foreign markets on the basis of mutual dependency, increasing in productivity and competiveness of country's economy, especially small and medium enterprises should promote for adding the potential value on the creativity and the innovation, focused on bringing the local wisdom as the intellectual property for further Research \& Development, passing on the knowledge and applying the commercial usability also the creating added value for the manufacturing sector with sufficiently both in quantity and quality which are building availability for entering the ASEAN in personnel development (The Eleventh National Economic and Social Development of 2012-2016: 9-20)

To promote of the community's economy is the major policy that the government should manage to enhance the economic strength. The handicraft products play a key role in economics and local society level for helping about community's income, decrease migration into the cities, create economic prosperity for the community and influence to country's economy. The handicraft product development to have a quality standard, unique and pattern as the needed of the market which is one of the government policies to promote Thai handicraft products level should be competitive in the market. At present, Thailand export including the handicrafts have a serious 
competition that make a trade barrier, thus, handicraft products development in term of material for producing, in term of beauty, a unique in accordance with the domestic and foreign markets requirement are important to increase more demand in the market.

The art of Thai handicraft related to Thai traditional life style owning to concern with a living of people all levels, aims to an important usability, the handicraft pattern had been developed based of technician skills and improvement for a better usability, therefore, developing and improving must use the knowledge and selecting materials for responding the usability, completely.

The handicrafts have weaknesses, strengths and opportunities for developing in the future. From a study of Department of Industrial Promotion had found the handicrafts strengths were as a cultural values as well as passing on the original individual unique, easy production method also not complicated, be able to use material at the local area for processing with do not destroy the natural resource and environment, not much money for investment that could be developing as the career for the villagers with decreased the labors migration into the city, the weakness were the production process take a lot of time, diseconomies of labor, not suitable for business competition, the producers did not focus on the quality control, unmotivated, do not have the information also the creation for developing about the production method as well as the business operation, the opportunities were the distinctive unique, trends of using Thai's commodity, general production method also less investment and the public and private sectors had paid attention to promote each other, thus, that showed the handicrafts had the opportunities for further development. Although many sectors had assisted to promote, they still had the limited problems such as the production method, the problems were lack of raw materials or a low quality, the obsolete equipment affected to the processing slowly, the shortage of skilled craftsmen and lack of knowledge for making a new pattern product with standard quality (Department of Industrial Promotion, 2012. [Online]). Owning to that problems, the report of the study had been suggestion the operations as well as optimal strategies such as management strategy and technology development strategy, the developing of raw materials pattern as well as production method for quality such as water hyacinth products, weaving products and pottery products, however, the important problem of development for promoting product as they must develop since a raw material, pattern, production method technique, collaboration, public relation also indoctrination for producers to make a local handicrafts as a source of creating the second career of villagers which should be encouraged and supported very seriously. Owing to facing of several problems, if it had been promoted with the properly direction by an obvious framework, continuous and comprehensive under the cooperation from all the parties concerned with seriously that would assist Thai's handicrafts expanded effectively which was the important way to assist the country's economy restored as well as to maintain Thai's unique, decreased labors migration, income distribution to the region which as the important foundation of country development for sustainable growth.

The basketwork is the art of handicraft which could be created in general, currently, many local basketwork have general accepted which highly skilled as well as magnificent pattern such as Yan Lipao basketwork of Nakhon Si Thammarat province, Phanat Nikhom basketwork and Angthong basketwork etc., the basketwork from local areas have inherit from the ancestors for a long time, nevertheless, the social, economic as well as Thai's living have change at the present, a demand of using a basketwork in daily life as decreased, besides, a certain types of raw material is rather expensive and difficult to find that initiate a new raw material such as water hyacinth, midrib of coconut, string made of banana tree and plastic for producing in the basketwork together with developing a new pattern as different from the original in order to accordant consumer's requirement such as applying between Lai Kid pattern and bamboo container become a weaved bag or some locality still have conserved with traditional style such as a small wicker basket, a bamboo basketwork refinement of natives from Tambon Bangchoacha, Pothong district at Angthong province and Phanat Niknom distinct at Chonburi Province etc., many techniques attempt to bring the weaving techniques and raw materials from each of local area for usability as much as possible. That should be an alternative guideline for developing of Thai basketwork adapt to the social and economic changes.

The pottery is a general art of handicrafts that in all regions of the country, they have been produced both manufacturing industry and an industrial craft as a traditional native style of each local areas by the art of handicraft characteristic with a fair price of villagers and most of them still conserve the traditional pattern on the local trend especially, now a day the pottery container for using in everyday still have produced the pottery glaze by industrial craft style in many local areas such as Ratchaburi pottery glaze, Oon Noi pottery glaze at Samut Sakorn province as well as many production sources in Chiang Mai and Lampang province. Therefore, Thai's pottery as the art of handicraft which have still produced with a native style in the present, having produced with uncertain neither unstable thus there should encourage and support for conserving the art of handicraft of Thai for a long time. 
Presently, the pottery production development have developed by imitating the basketwork production pattern with bringing the clay into strips and switching weaves it according to the basket form or using bamboo wickerwork adding as the handle of the container or wrapping cover around the pottery product that give an expression of the development have been a separated idea design include the production from each other that affected the identity of a beautiful material including the pattern form have not been harmonious neither separated as well as the usability have not been suitable. Hence, the integration of the pottery handicraft and the basketwork handicraft should study especially about the identities of the material, the characteristic, the productivity, the beauty as well as the marketing of both the pottery and the basketwork as conduce to the integration with suitable combination design as from the material and production that conduct to a unique design, an easy for using, a beauty, integrated with the unity.

According to principle and that factors for solving lack of design knowledge and a new product pattern development, researcher had realized on the necessity of the operated knowledge management about promoting of the handicraft pattern product design and development for getting the quality and developing the great wisdom of both handicraft sciences conduce to the examination of processing, material and production method of both of the pottery and the basketwork investigation bring to a new dimension and more effective production method including the creative thinking process of developing and making a new product for responding the needs of solving problem of groups to have a product pattern with correspond the marketing demand which is an approach to motivate promotion campaign as the effect to increase a study of the investigation and conservation the art of handicraft that conduce to the benefit of the creating community network, adding the craft pattern variety , developing and promoting turn into the international style with the gifts, the souvenirs, the appliances as well as the decorative items, besides the adding handicraft value with varieties which give an expression of local wisdom also adding the distribution channel in the global market that is the important approach for enhancing the market supply although the quality development conduce to increase the exportation also assisting approach the producers of both the pottery and basketwork in the communities to get the prototype and productivity in order to product development with getting from the research conduce to product development with varieties pattern style of their community that influencing a stronger community economy, a strong assistance that bring the knowledge to both private and public educational institution with getting the international standard acceptation, raising a craft skilled as to basic standard of product quality, supporting a party force, developing within the country from the local community to the concerned agencies, focus on the creating networks and the local community efficiency therefore being awareness and preparing of changing current, supporting of the area development mechanism that conduce to the strategy formulation of the province and the provinces group development. Consequently, to achieve the usability in sustainable development about a study of the integration of the pottery handicraft and the basketwork handicraft for developing a strength community economy that bring to create the prototype, developing production method that making a living, increasing a revenue affect to a quality of life, a community economy as well as a culture having a sustainable consistency and balance which is a presentation of developing guideline about a local knowledge for further development as well as supporting a revenue to handicraft producers which is an approach to create a progress for the community to be able improve people's well-being in the community getting better by creating a product based of principle knowledge have become to product with a quality and having a unique obviously correspond with a domestic and global demands by a local knowledge basic principle to the international as they could earn one's living, creative thinking, building human resource owning to the product not only a goods but also the thinking process include the creativeness, the discovery, the conservation of the art and cultural handicraft knowledge, a local knowledge for further development, the handicraft knowledge sciences exchange for becoming as the handicrafts product with getting on quality, prominent point, selling point, wildly being well known both within the country as well as the global as well as conserving and passing on Thai's art and cultural and the handicrafts still not disappear that lead to acquire answers of research with the researcher

1. The conducting of the basketwork handicraft identity applying with the pottery handicraft product for supporting a strength community economy that should do it or not? If it should do, how should the process they do it?

2. The experimental product design development of the pottery together with the basketwork handicraft to get a beautiful unique corresponding conform to a market demands that should do it or not? If it should do, how should the process they do it?

3. The evaluation of market testing result from the developed handicraft product that conclude to producer's guideline for usability that should do it or not, If it should do, how should the process they do it? This research result bring to a useful development for the producers as well as the entrepreneurs of the handicraft product to 
get a knowledge of the art of handicraft academy and to get the pottery and basketwork handicrafts skilled for further integration that bring to a new process, a new production as well as a new quality standard product that helping a group of pottery and basketwork community which facing a problem of product development owning to they have been get the guidelines and production method to develop handicraft product pattern of group to meet the market demand that could be able commercial competitiveness correspond to a national strategy and also assists to promote and to create a learning process of value added to other handicraft products that could apply to their own which is the communities database creation of the communities or the concerned agencies that have required a handicraft product development and also inherited the wisdom, conserved and introduced the art of culture for the next generations have perceived the art and cultural, applying from both of handicrafts conduce to a new handicraft product that keep remaining and disappearing forever.

\section{Research Objectives}

1. To study the art of handicraft identity of the basketwork applying together with the pottery handicraft.

2. To examine a design operation and the pottery handicraft product development together with the basketwork handicraft development to a beautiful identity and suitable for market demand.

3. To evaluate the market testing of a developed handicraft product.

\section{Research Conceptual Framework}

A conceptual framework the pottery handicraft product development integrated with the basketwork for adding value community product

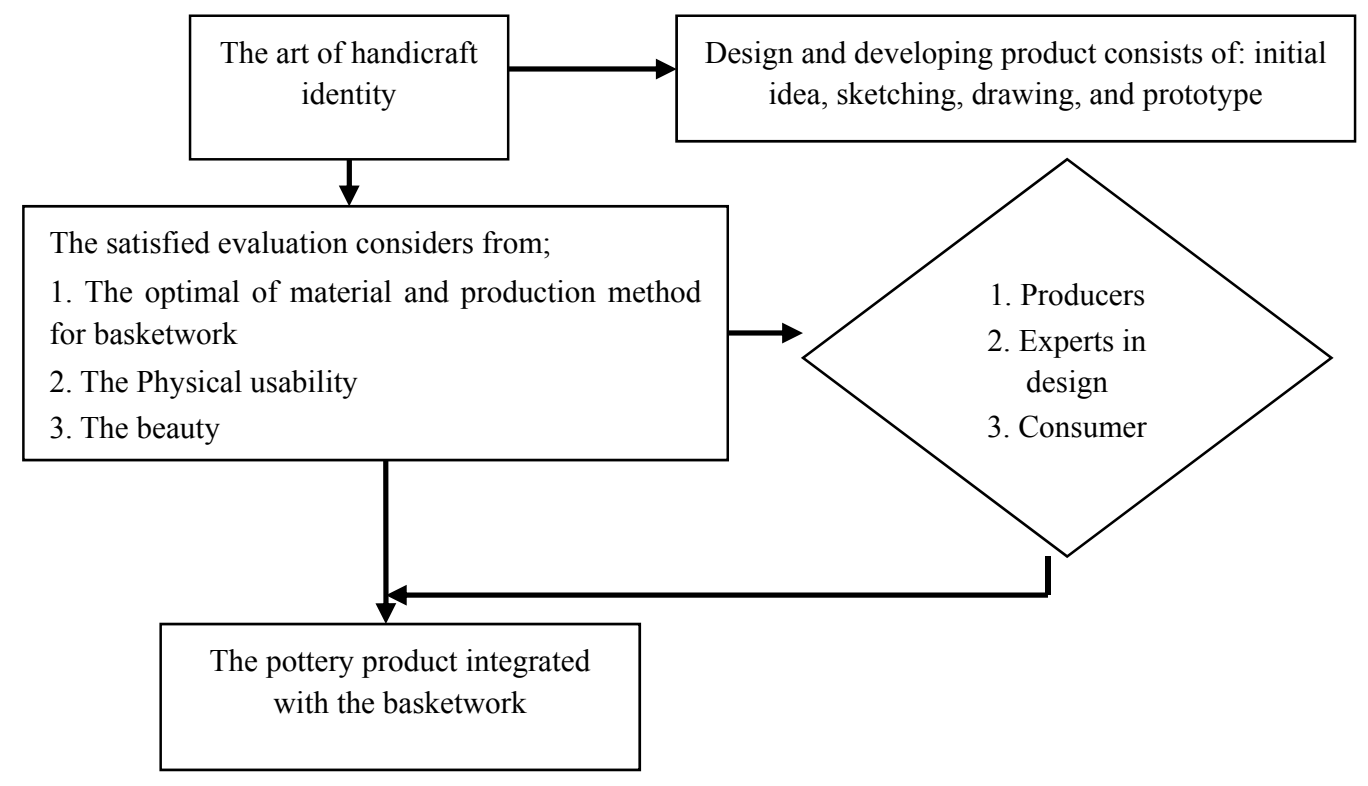

Figure 1. Conceptual framework

\section{Research Methodology}

This research, research had used a qualitative research method to evaluate the result of pattern design utilized to the pottery product integrated with the basketwork.

\subsection{Scope of Research}

The delimitation of this research included:

(1) Area scope and sampling of study: 2 groups of handicraft product producer, using the purposive sampling method with qualified selecting from product groups having experiences at least 10 years

1.) The basketwork handicraft product group: Sarasilp Bang Chaung Cha group.

2.) The pottery handicraft group: Ceramic product group.

They had provided product information and suitable conducting the art of handicraft product concerned with:

1. Factors concerned with the aims to creative achievement. 
2. Creating process, limitation, problems and production process.

3. Physical characteristic and pattern of achievement identity.

1.2 The 3 product design experts which selected by having experiences about souvenirs, expert and specialize in product design field at least 5 years in order to consult about a design result, adjust the style in accordance with the aims of research and evaluate a design result.

1.3 Consumer sampling group were 400 people by using a purposive sampling method of the place at 2 handicraft product shop namely: 1) Chatuchoak Weekend Market and 2) JJ Mall, inquiring with an accidental sampling method for getting the art of basketwork handicraft identity and opinions toward the pottery handicraft product before-after developed.

1.4 Scope of design: Researchers have designed the pottery together with the basketwork handicraft.

\subsection{Research Instrument}

Stage 1. To study the art of handicraft identity of the basketwork applying together with the pottery handicraft.

1. The conference arrangement for explaining the activity operation guideline, a plan and operation method to producer group

2. Study of the art of basketwork handicraft identity for applying together with pottery handicraft.

3. Study and analyze product types for developing to prototype product with focus on a design condition in target area, marketing, materials and production method of pottery handicraft product and basketwork handicraft product to increase value addition along with market trend, by mean of collecting data from the target group of producer at fieldwork with interviewing and using structural questionnaire, observing to study of problems, solving problem guideline and developing guideline by using a Participatory Action Research as well as study and analyze market demand trend with corresponding producers' group.

4. Synthetic principle and developing process to use as the product development guideline for producer group of pottery handicraft product and producer group of basketwork handicraft product

5. Conclusion of study and analyze about the original product, the wisdom, community demand and market demand trend for using as a design data and development in the next step.

Stage 2. To examine a design operation and the pottery handicraft product development together with the basketwork handicraft development to a beautiful identity and suitable for market demand.

1. The process of design and product development of pottery handicraft together with basketwork handicraft were examined by producers group lead to getting a skilled, guideline and production method that conduce to design guideline as well as the pattern of handicraft product with suitable, beautiful with corresponding market demand, therefore, to examine the process operation, production method of pottery handicraft product and basketwork handicraft that conduce to the prototype and optimal process with having a neat and beautiful identity.

2. The product development was evaluated by design experts and marketing experts for getting the information about the opinions toward product in term of usability, in term of beauty, in term of value and identity and in term of marketing by using in depth interview.

3. Conclusion data result from the process of design operation examination and product development of pottery handicraft and basketwork handicraft.

\section{Stage 3. To evaluate the market testing of developed handicraft product.}

Market testing though evaluated product development process in term of marketing by people and tourists in Bangkok at handicraft product shop in Bangkok for getting information about the opinions toward a new handicraft product from the development in term of usability, in term of beauty, in term of value and identity and in term of marketing

\section{Data Collection and Data Analysis}

A study of identity of the art of basketwork handicraft applying with pottery handicraft, researcher had presented the result of research into 2 parts consists of: a result of the art of basketwork handicraft identity and a result of consumer sampling group opinions in terms of the art of basketwork handicraft identity and product demand that getting integrated with the pottery, therefore, this results would been used as the data for design process and for the further development of pattern product, results were as follows:

Stage 1 To study the art of basketwork handicraft identity. 
Making a basketwork of Bang Kachao sub-sistricts, Phothong district, Ang-thong province have inherited from the ancestor, in the pass, the basketwork had been used as the container in daily life such as basket, bamboo basket, animal traps, after that, it had been modified as the appliance with conform to a life style of the present such as a bag etc., as the present for senior, as the souvenirs on special days, used as the provincial slogan in official, afterwards, the basketwork pattern was developed to other forms and a new pattern with modern style, adding value to product, being demanded both in country and foreign countries, product is neat, delicate and beautiful, the pattern has blended together between the wisdom and Thai's unique, the pattern was adjusted applying by conducting fabric pattern to blend within the product that make a difference and more value added, having a variety colors, the important characteristic of the principle and consideration of the basketwork production consists of:

1. Different structure is accordance with the shape characteristic such as the vertical line and the horizon line, making a thin bamboo strips to get required size, most of vertical line should have a width and a thickness more than horizon line

2. A weaving for forming to several shapes must have a receptacle inside in order to get the form and the curvature on desirable, thus, the earthenware production that form with the basketry should have a gab or a curvature to handle the basketry.

Stage 2 Analysis the opinions of the art of basketwork handicraft identity and product demand conduce to a design guideline.

Researcher had studied the opinions of 400 consumer as sampling group, inquired at a handicraft shop in Ang-Thong Province, samples were selected by the accidental sampling with close-ended form and photos for asking the opinions of people and tourists toward product, focus on product pattern, materials, the original pattern and product demand that conduct to a new product design, the questionnaire have set the answers as Check Lists Form and Rating Scale Form, the period of explore data between February to March 2017, result as the follows:

Table 1. Number and percentage of consumer sampling group

\begin{tabular}{lccc}
\hline Order & List of items & Number & Percentage \\
\hline 1.Gender & Female & 261 & 65.25 \\
& Male & 139 & 34.75 \\
2.Consumer & Local Person & 221 & 55.25 \\
& Tourist & 179 & 44.75 \\
3. Age & $18-27$ years old & 35 & 8.75 \\
& $28-37$ years old & 81 & 20.25 \\
& $38-47$ years old & 122 & 30.50 \\
& Over 48years old & 162 & 40.50 \\
4. Income & Under 10000 Bath & 60 & 15.00 \\
& $10001-18000$ Bath & 95 & 23.75 \\
& $18001-26000$ Bath & 108 & 27.00 \\
5. Would you like to buy basketwork product? & I would & 246 & 61.50 \\
& I would not & 154 & 38.50 \\
6. Would you like to buy pottery product? & I would & 289 & 72.25 \\
& I would not & 111 & 27.75 \\
\hline
\end{tabular}

From the information with concerned for using as applying product pattern guideline found the general information of respondents that have effect on the opinion in various points divided into consumer sampling group as females were 65.25 percentage, males were 34.75 percentage, divided into local persons were 55.25 percentage and tourists were 44.75 percentage, divided into the age found mostly the age over 48 years old were 40.50 , secondly the age during 38-47 years old were 30.50 percentage, the age during 28-37 years old were 20.25 percentage and the age during 18-27 years old were at least with 8.75 percentage, the respondents had income per month divided into a large 4 groups with mostly income per month over 26,000 bath were 34.25 percentage, secondly, income 18,001-26,000 bath were 27.0 percentage, income 10,001-18,000 bath were 23.75 percentage and consumers' income under 10,000 bath were the least as 15.0 percentage. 
Result of consumers' opinions and requirement for choosing and reason to purchase the basketwork handicraft product in order to the guideline of a new product development integrated with the pottery, which 400 consumer sampling group opinion towards the basketwork product revealed they would like to buy basketwork product as 61.50 percentage, they would not like to buy basketwork product as 38.50 percentage and the consumer sampling group would like to buy the pottery product as 72.50 percentage and they would not like to buy the pottery as 27.75 percentage.

Table 2. The opinion average of consumer sampling group towards the opinion for making decision to buy the basketwork product. $\mathrm{N}=400$

\begin{tabular}{|c|c|c|c|c|}
\hline Order & List of items & Average & S.D. & Level \\
\hline \multirow[t]{8}{*}{1.} & $\begin{array}{l}\text { Which level you have to make decision causes buying } \\
\text { the basketwork product? }\end{array}$ & & & \\
\hline & Buying for their own & 4.68 & 0.47 & The highest \\
\hline & Buying for the others & 4.43 & 0.51 & The highest \\
\hline & Exotic unique product & 4.65 & 0.54 & The highest \\
\hline & Durable strength & 4.57 & 0.64 & The highest \\
\hline & Portable size with convenient & 3. 86 & 0.66 & High \\
\hline & Expensive price & 3.21 & 0.75 & Medium \\
\hline & Total & & & \\
\hline \multirow[t]{8}{*}{2.} & $\begin{array}{l}\text { Which level you have to make decision causes } \\
\text { buying the pottery product? }\end{array}$ & & & \\
\hline & Buying for myself & 4.57 & 0.47 & The highest \\
\hline & Buying for the others & 4.63 & 0.51 & The highest \\
\hline & Exotic unique product & 4.60 & 0.54 & The highest \\
\hline & Durable strength & 3.76 & 0.64 & High \\
\hline & Portable size with convenient & 4.53 & 0.66 & The highest \\
\hline & Expensive price & 3.24 & 0.75 & Medium \\
\hline & Total & & & \\
\hline
\end{tabular}

As shown in Table 2, a study of making decision to buy the original product of consumer sampling group had the opinions toward the cause of making decision to buy basketwork product which was the highest level as buying for their own at the average 4.68 , secondly, the exotic unique product at the average 4.65 , the durable strength at the average 4.57 and the consumer sampling group with buying for the others was a highest level with the average, respectively, and considered with portable size to take with convenient at the average 3.86 and considered with the price, if it getting with the expensive price that making decision to buy was a medium level at the average 3.21, A study of making decision to buy the original product revealed that the consumer sampling group had the opinions towards the cause of making decision to buy the pottery was buying for the others with the highest level at the average 4.63, secondly, the exotic unique product with the average 4.60 , buying for their own was the highest level with the average 4.57 and considered of the portable size with convenient with the average 4.53 , the durable strength with the average 3.76 and considered about the price, if it getting with the expensive price that making decision to buy was a medium level with average 3.21.

Table 3. The exploration of the opinions and consumer sampling group demand for conducing as the design guideline and product development

\begin{tabular}{cccc}
\hline Order & List of items & Number & Percentage \\
\hline $\begin{array}{c}\text { 1. If conducting the basketwork to produce together with } \\
\text { the pottery conduce to the appliance product, would it be }\end{array}$ & Suitable & 324 & 81.00 \\
suitable or not? & Not suitable & 76 & 19.00 \\
$\begin{array}{c}\text { 2. If conducting the basketwork to produce together with } \\
\text { the pottery conduce to product, what kind of the most } \\
\text { wanted product }\end{array}$ & Basket product & 168 & 42.00 \\
& Lamp product & 178 & 44.50 \\
& Home decoration products & 54 & 13.50 \\
\hline
\end{tabular}

As shown as the Table 3, the opinions of the consumer sampling group towards the opinions of product demand 
revealed that conducting the basketwork to produce together with the pottery conduce to the appliance product was suitable with the average 81.0 percentage and not suitable with the average 19.0 percentage, the type of appliance product that the consumer sampling group had the most wanted as the lamp product with the average 44.50 percentage, the basket product with the average 42.0 and home decoration products with the average 13.50 percentage.

The exploration result of the opinion and consumer sampling group demand for using as the guideline design and product development of the pottery handicraft product together with the basketwork found the first cause of making decision to buy the basketwork was buying for their own, secondly was the exotic unique product, durable strength and considered about the portable size to take with convenient, however, the cause of making decision to buy the pottery product for the others that revealed the consumer sampling group demand were the lamp product and basket product.

\section{Conclusion of Research Result}

The exploration result of consumer demand found the type of product that consumer had requirement as the lamp product and the basket product, researcher had designed and developed the pottery handicraft product together with the basketwork handicraft to have the beautiful identity that suitable on market demand that consists of:

1. A study result of product design experiment in order to achieve the pattern and pattern details of the pottery product that being integrated and produced together with the basketwork would be consideration about the connecting between the pottery and the basketwork as well as bringing together of parts of the pottery creation that connect with the basketwork, researcher had experimented design of earthenware edge connecting with the basketwork by connecting method that make 5 guidelines such as:

Guideline 1 The upper edge of container with beetle inside has been made the holes and spaced with 1 inch for binding the wicker on the top then using the weaving method by with pitch in the vertical line and binding with the wicker, as shown in Figure 2

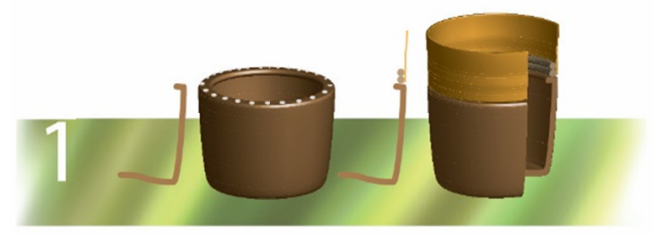

Figure 2. Container edge pattern as the part connected with the basketry method 1

Guideline 2 The upper edge of container stand upright, making the holes as low line below the upper edge with 3 inches, spaced for making a hole with $0.5-1$ centimeter, for binding the vertical line in order to increasing strength, as shown in Figure 3

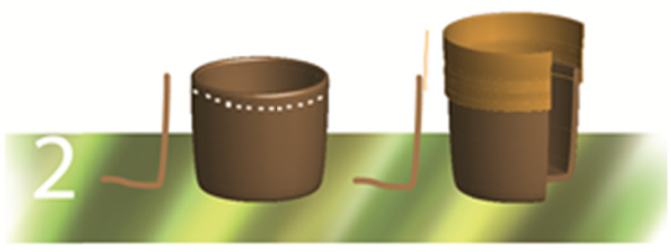

Figure 3. Container edge pattern as the part connected with the basketry method 2

Guideline 3 The upper edge of container stand upright and overlap inside with 0.5 centimeter which was made the holes below the upper edge with 3centimeter, space for making a hole with 1 centimeter to bind the vertical line, overlap distance to support the basketry thickness in order to get a row that align with both materials, as shown in Figure 4

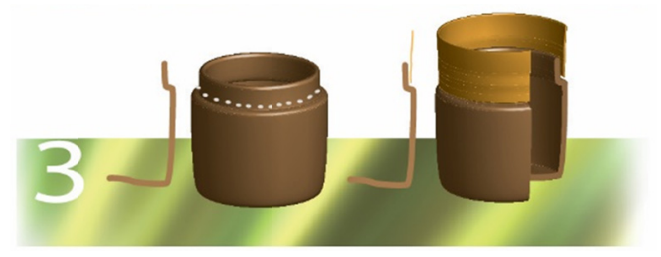

Figure 4. Container edge pattern as the part connected with the basketry method 3 
Guideline 4 The upper edge container indent inside as a niche about 0.5 centimeter, using a thickness bamboo stripe tightens around a spaced niche, making a hole below the upper edge with 3 centimeter, spaced for making a hole with 1 centimeter for weaving and tightening with bamboo stripe and cover it in order to increase a strength as well as a thickness of a basketry aligned with edge both materials, as shown in Figure 5

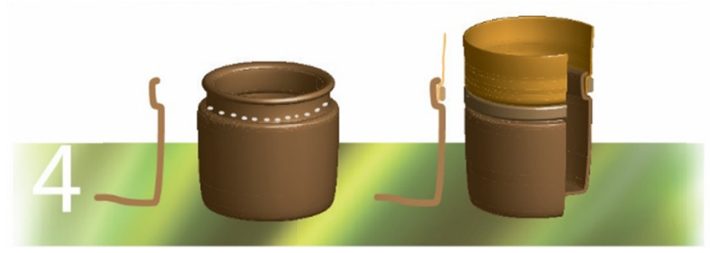

Figure 5. Container edge pattern as the part connected with the basketry method 4

Guideline 5 Upper edge of container have a land edge inside for supporting basketry edge, making the holes below the upper edge with 3 centimeters, spaced for making an each hole with 1 centimeter, for weaving and tightening the bamboo strip, covered into the basketwork, that appearing the edge of earthenware is outside the basketwork, as shown in Figure 6

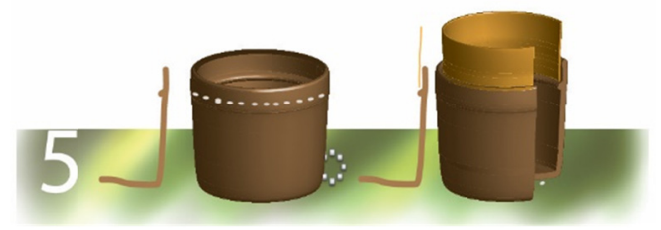

Figure 6. Container edge pattern as the part connected with the basketry method 5

Data collection of edge earthenware at the part connected with the basketwork, the data was collected by researcher form 3 pottery producers and 3 basketwork producers about the production capabilities, complicating, and suitability for forming the basketry production method that revealed, the evaluated results of patterns and production method could produce with all sketches, 3 producers have the same conclusion as the $3^{\text {rd }}$ guideline is the most suitable production, with both of pottery container pattern and weaving method to from the basketry.

Table 4. Analysis results of the earthenware pattern with the part connecting with the basketwork by 3 pottery producers $(\mathrm{N}=3)$

\begin{tabular}{|c|c|c|c|c|c|c|c|c|c|c|c|}
\hline & \multirow{3}{*}{ List of items } & \multicolumn{10}{|c|}{ Optimum item } \\
\hline & & \multicolumn{2}{|c|}{ Pattern 1} & \multicolumn{2}{|c|}{ Pattern 1} & \multicolumn{2}{|c|}{ Pattern 1} & \multicolumn{2}{|c|}{ Pattern 1} & \multicolumn{2}{|c|}{ Pattern 1} \\
\hline & & $\bar{\chi}$ & S.D. & $\overline{\bar{\chi}}$ & S.D. & $\overline{\bar{x}}$ & S.D. & $\overline{\bar{x}}$ & S.D. & $\bar{\chi}$ & S.D. \\
\hline 1 & $\begin{array}{l}\text { Optimum to materials and } \\
\text { pottery production method }\end{array}$ & & & & & & & & & & \\
\hline 1.1 & $\begin{array}{l}\text { Optimum pattern for } \\
\text { forming by throwing }\end{array}$ & 5.00 & 0.00 & 5.00 & 0.00 & 5.00 & 0.00 & 5.00 & 0.00 & 1.00 & 0.00 \\
\hline 1.2 & $\begin{array}{l}\text { Optimum pattern for } \\
\text { forming by slip casting) }\end{array}$ & 5.00 & 0.00 & 5.00 & 0.00 & 5.00 & 0.00 & 5.00 & 0.00 & 1.00 & 0.00 \\
\hline 1.3 & $\begin{array}{l}\text { Optimum pattern for } \\
\text { forming by free form }\end{array}$ & 5.00 & 0.00 & 5.00 & 0.00 & 5.00 & 0.00 & 5.00 & 0.00 & 5.00 & 0.00 \\
\hline \multirow[t]{2}{*}{1.4} & Upper edge easy to produce. & 5.00 & 0.00 & 5.00 & 0.00 & 5.00 & 0.00 & 5.00 & 0.00 & 2.00 & 0.00 \\
\hline & $\begin{array}{c}\text { The optimum production } \\
\text { with total }\end{array}$ & 5.00 & 0.00 & 5.00 & 0.00 & 5.00 & 0.00 & 5.00 & 0.00 & 2.25 & 0.00 \\
\hline
\end{tabular}

As shown at the Table 4, the earthenware pattern were optimal for production which could produce by throwing, slip casting and free form, the earthenware pattern 5 with could produce particularly with free form due to the upper edge was difficult to produce and when the patterns were evaluated by basketwork produced revealed the pattern which could be able for weaving with bamboo strip were pattern 1 and 3 as the upper edge pattern of container with optimum forming, easy optimum assembling method, strengthen pattern, easy to repair when get damaged, the optimum production overall was the highest level with average 5.00, pattern 2,4 and 5 that found the earthenware pattern as part connected with the basketwork was not optimum to produce with basketwork, as shown at Table 5 
Table 5. Analysis results of the earthenware pattern with the part connecting with the basketwork by 3 basketwork producers $(\mathrm{N}=3)$

\begin{tabular}{|c|c|c|c|c|c|c|c|c|c|c|c|}
\hline & \multirow{3}{*}{ List of items } & \multicolumn{10}{|c|}{ Optimum level } \\
\hline & & \multicolumn{2}{|c|}{ Pattern1 } & \multicolumn{2}{|c|}{ Pattern1 } & \multicolumn{2}{|c|}{ Pattern1 } & \multicolumn{2}{|c|}{ Pattern1 } & \multicolumn{2}{|c|}{ Pattern1 } \\
\hline & & $\bar{x}$ & S.D. & $\overline{\bar{x}}$ & S.D. & $\bar{x}$ & S.D. & $\bar{x}$ & S.D. & $\bar{\chi}$ & S.D. \\
\hline 1. & $\begin{array}{l}\text { The optimum to materials and } \\
\text { basketwork production method }\end{array}$ & & & & & & & & & & \\
\hline 1.1 & $\begin{array}{l}\text { Optimum pattern of container edge } \\
\text { for forming by weaving }\end{array}$ & 5.00 & 0.00 & 1.00 & 0.00 & 5.00 & 0.00 & 1.00 & 0.00 & 1.00 & 0.00 \\
\hline 1.2 & Easy optimum assembling method & 5.00 & 0.00 & 1.00 & 0.00 & 5.00 & 0.00 & 1.00 & 0.00 & 1.00 & 0.00 \\
\hline 1.3 & Strengthen pattern & 5.00 & 0.00 & 1.00 & 0.00 & 5.00 & 0.00 & 1.00 & 0.00 & 1.00 & 0.00 \\
\hline \multirow[t]{2}{*}{1.4} & Easy to repair when get damaged & 5.00 & 0.00 & 1.00 & 0.00 & 5.00 & 0.00 & 1.00 & 0.00 & 1.00 & 0.00 \\
\hline & The optimum production overall & 5.00 & 0.00 & 1.00 & 0.00 & 5.00 & 0.00 & 1.00 & 0.00 & 1.00 & 0.00 \\
\hline
\end{tabular}

The next steps of experimental design as researcher had made sketch idea which were the prototypes such as 6 baskets and 6 lamps, according to the concept from exploration and data analysis at beginning which having difference of form pattern, the adhere of handles pattern, the size and assembling of basket, thence, brought the idea sketches to evaluate by the design experts and producers, analyzing and selecting the guideline pattern with optimum to production method, strength and beauty, as shown in Figure 7-8.

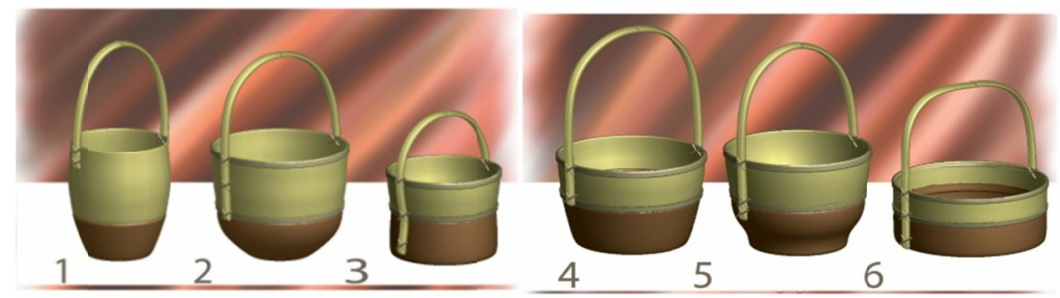

Figure 7. Basket product patterns

Table 6 . Analysis result of the optimum of assembling method of handles basket by 3 basketwork producers

\begin{tabular}{ccccc}
\hline Order & List of items & Average & S.D. & Level \\
\hline 1. & How to handle the basket assembly is appropriate. & & \\
& Pattern 1 & 1.00 & 0.00 & Lowest \\
Pattern 2 & 1.00 & 0.00 & Lowest \\
Pattern 3 & 1.00 & 0.00 & Lowest \\
& Pattern 4 & 1.00 & 0.00 & Lowest \\
& Pattern 5 & 5.00 & 0.00 & Highest \\
& Pattern 6 & 5.00 & 0.00 & Highest \\
\hline
\end{tabular}

As shown at the Table 6, analysis results of pattern and adhering of basket handles by basketwork producers revealed that pattern 5 and 6 having the optimum pattern for the handles basket assembling method was the highest level which optimal to production method, strength, be able supporting a weight and beauty with average 5.00 , on the other hand, the pattern 1-4 having the optimum pattern for the handles basket assembling method was the lowest level with average 1.0.

Table 7. Analysis results of the beautiful optimum of figure form by 3 basketwork producers

\begin{tabular}{ccccc}
\hline Order & List of items & Average & S.D. & Level \\
\hline 2. & Beautiful optimum of figure form & & & \\
& Pattern 1 & 1.00 & 0.00 & Lowest \\
Pattern 2 & 5.00 & 0.00 & Highest \\
Pattern 3 & 1.00 & 0.00 & Lowest \\
Pattern 4 & 5.00 & 0.00 & Highest \\
& Pattern 5 & 5.00 & 0.00 & Highest \\
& Pattern 6 & 1.00 & 0.00 & Lowest \\
\hline
\end{tabular}


As shown at the Table 7 found, a beautiful optimum of figure form as pattern 2,4 and 5 was the highest level with average 5.00, on the other hand, pattern 1,3 and 6 found a beautiful optimum of figure form was a lowest level with average 1.00 .
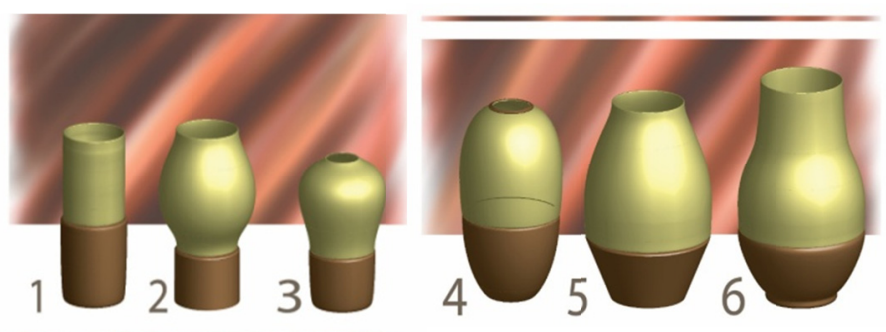

Figure 8. Lamp product pattern

Table 8 . Analysis result of lamp patterns with the production method by 3 basketwork producers

\begin{tabular}{ccccc}
\hline Order & List of items & Average & S.D. & Level \\
\hline 1. & The optimal lamp pattern & & & \\
& Pattern 1 & 5.00 & 0.00 & Highest \\
Pattern 2 & 5.00 & 0.00 & Highest \\
Pattern 3 & 5.00 & 0.00 & Highest \\
Pattern 4 & 5.00 & 0.00 & Highest \\
Pattern 5 & 5.00 & 0.00 & Highest \\
& Pattern 6 & 5.00 & 0.00 & Highest \\
\hline
\end{tabular}

As shown at the Table 8 found that all lamp patterns had the optimum to the production method, strength, supporting weight and beauty as the highest level with average 5.0

From the analysis result of basket and lamp pattern evaluation, researcher had experimented to produce the basket prototypes and the lamp prototypes, as shown in Figure 9-10

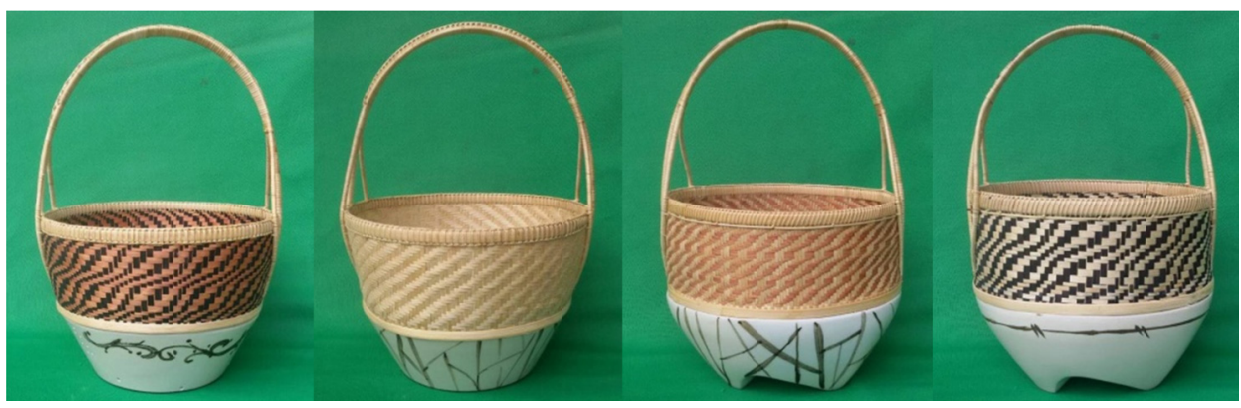

Figure 9. The basket product prototype

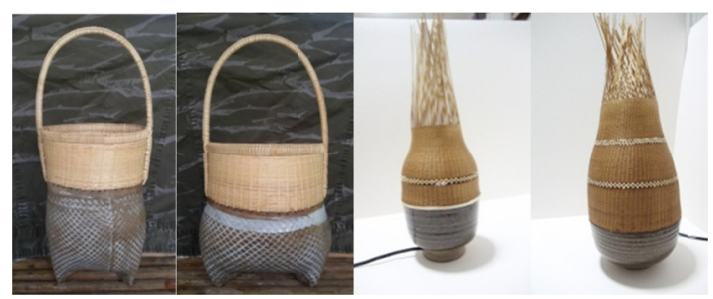

Figure 10. The basket product prototype and the lamp product prototype

After creating the souvenirs product prototype from the participation process amount students, producers' community and research team, conducting the prototypes to market testing by 400 consumer sampling group ( $\mathrm{n}=$ $400)$ to evaluate the optimum opinions, the result as shown below: 
Table 9. Number and percentage of sampling group divided by gender

\begin{tabular}{cccc}
\hline Order & List of items & Number & Percentage \\
\hline 1. & Gender & & \\
Female & 221 & 55.20 \\
Male & 179 & 44.80 \\
Aged & & \\
$18-27$ years old & 41 & 10.30 \\
$28-37$ years old & 92 & 23.00 \\
$38-47$ years old & 100 & 25.00 \\
Over 48 years old & 167 & 41.80 \\
Monthly income & & \\
Under 10000 baths & 69 & 17.30 \\
$10001-18000$ bath & 130 & 32.50 \\
$18001-26000$ bath & 90 & 22.50 \\
Over 26001 bath & 111 & 27.80 \\
\hline
\end{tabular}

As shown at Table 9 found consumer sampling group as female were 55.20 percentage and male were 44.80 percentage which the aged between 38-47 years old were the most interesting at 41.80 percentage, secondly, aged over 48 years old were 25.00 percentage, aged between 28-37 years old were 23.00 percentage and aged between 18-27 were the less interesting at 10.30 percentage, mostly consumer sampling group had monthly income $10,000-18,00$ bath were 32.50 percentage, secondly, monthly income over 26,001 bath at 27.80 percentage, monthly income $18,001-26,000$ bath at 22.50 percentage and monthly income under 10,000 bath were the lowest income at 17.30 percentage.

A study results of market testing product

A study of the opinions and market testing of basketwork handicraft product integrated with the pottery, consumer had opinions and satisfaction toward product that found they had satisfied with all 3 products that could be conclusion as:

Table 10. Analysis result of basket product prototype type 1

\begin{tabular}{lllc}
\hline Order $\quad$ List of items & $\bar{x}$ & S.D. & Opinion level \\
\hline 1. $\quad$ A Physical usefulness (Practical Function) considered form & & & \\
$\quad$ Easily convenient usability & 4.53 & 0.50 & Highest \\
1.2 The optimum of size & 4.38 & 0.53 & Highest \\
1.3 Safety for usability & 4.55 & 0.52 & Highest \\
1.4 Maintenance, Cleaning & 4.26 & 0.72 & Highest \\
$\quad$ 1.5 Durable strength & 3.96 & 0.71 & High \\
A total of physical usefulness (Practical Function) & 4.34 & 0.59 & High \\
2. A Beauty (Aesthetic Function) Considered from $\quad$ & & \\
$\quad$ 2.1 The optimum of pattern composition & 4.39 & 0.54 & High \\
$\quad$ 2.2 Beauty in terms of color and pattern & 4.39 & 0.68 & Highest \\
$\quad$ 2.3 Interesting unique & 4.70 & 0.54 & Highest \\
$\quad$ 2.4 Product value & 4.63 & 0.50 & Highest \\
A total of beauty (Aesthetic Function) & 4.53 & 0.56 & Highest \\
A total of product design evaluation & 4.44 & 0.57 & High \\
\hline
\end{tabular}

As shown at the Table 10 that analysis result of basket product prototype type 1: the consumer opinions could be concluded as the basket product type had a satisfaction over all was the highest level $(\bar{\chi}=4.44)$ with could be classified into 4 items, namely, the optimum in term of beauty with total was the highest level $(\bar{\chi}=4.53)$ as in term of pattern color and pattern, in term of interesting unique and in term of supporting product value were the highest level ( $\bar{x}=4.34)$, safety for usability and easily convenient usability.

A suggestion of product was conducting the basketwork to create a product together with the pottery might be 
difficult to take care, disadvantage effect on the basketwork that might be easily damage as influence for usability with short time when compared with the pottery, however, if the product had not used with a care that affect to the pottery might be easily damaged too.

Table 11. Analysis of basket product prototype type 2

\begin{tabular}{llccc}
\hline Order & List of items & $\bar{\chi}$ & S.D. & Opinion level \\
\hline 1. & A Physical usefulness (Practical Function) considered form & & & \\
$\quad$ Easily convenient usability & 4.44 & 0.59 & High \\
1.2 The optimum of size & 4.57 & 0.74 & High \\
1.3 Safety for usability & 4.65 & 0.69 & High \\
1.4 Maintenance, Cleaning & 4.35 & 0.82 & High \\
1.5 Durable strength & 4.18 & 0.75 & High \\
A total of physical usefulness (Practical Function) & 4.44 & 0.71 & High \\
2. A Beauty (Aesthetic Function) Considered from & & & \\
$\quad$ 2.1 The optimum of pattern composition & 4.51 & 0.55 & Highest \\
$\quad$ 2.2 Beauty in terms of color and pattern & 4.54 & 0.55 & Highest \\
$\quad$ 2.3 Interesting unique & 4.75 & 0.50 & Highest \\
$\quad$ 2.4 Product value & 4.45 & 0.50 & High \\
A total of beauty (Aesthetic Function) & 4.56 & 0.52 & Highest \\
A total of product design evaluation & 4.51 & 0.61 & High \\
\hline
\end{tabular}

As shown at the Table 11, analysis result of basket prototype type 2, the opinions consumer sampling group with having a satisfaction on overall was the highest level $(\overline{\mathcal{X}}=4.44)$ that could be classified into the items as the optimum in terms of beauty with total (Aesthetic Function) was the highest level $(\bar{\chi}=4.56)$ as in term of color and pattern, in term interesting unique and in term of supporting product value were the highest level $(\bar{x}=4.44)$, safety for usability and easily convenient usability.

A suggestion of product was conducting the basketwork creating product together with the pottery might be difficult to take care, disadvantage effect on the basketwork that might be easily damage as influence for usability with short time when compared with the pottery, however, if the product had not used with a care that affect to the pottery might be easily damaged too, the basket product prototype type 2 were strengthening than basket prototype type 1 , however, it had the limit usability as compare with a size and a width.

Table 12. Analysis of lamp product prototype

\begin{tabular}{|c|c|c|c|c|}
\hline Order & List of items & $\overline{\bar{\chi}}$ & S.D. & Opinion level \\
\hline \multirow[t]{6}{*}{1.} & A Physical usefulness (Practical Function) considered form & & & \\
\hline & Easily convenient usability & 4.56 & 0.52 & Highest \\
\hline & 1.2 The optimum of size & 3.84 & 0.64 & High \\
\hline & 1.3 Safety for usability & 4.08 & 0.59 & High \\
\hline & 1.4 Maintenance, Cleaning & 4.69 & 0.50 & Highest \\
\hline & 1.5 Durable strength & 3.87 & 0.59 & High \\
\hline \multicolumn{2}{|c|}{ A total of physical usefulness (Practical Function) } & 4.20 & 0.56 & High \\
\hline \multirow[t]{5}{*}{2.} & A Beauty (Aesthetic Function) Considered from & & & \\
\hline & 2.1 The optimum of pattern composition & 4.62 & 0.76 & Highest \\
\hline & 2.2 Beauty in terms of color and pattern & 4.69 & 0.50 & Highest \\
\hline & 2.3 Interesting unique & 4.88 & 0.43 & Highest \\
\hline & 2.4 Product value & 4.47 & 0.55 & High \\
\hline \multicolumn{2}{|c|}{ A total of beauty (Aesthetic Function) } & 4.66 & 0.56 & Highest \\
\hline \multicolumn{2}{|c|}{ A total of product design evaluation } & 4.43 & 0.56 & High \\
\hline
\end{tabular}

As shown at the Table 12, analysis result of lamp product prototype, the opinions consumer sampling group that could be concluded: the product lamp having a satisfaction on overall was the highest level $(\bar{\chi}=4.43)$ that could 
be classified into the items as the optimum in terms of beauty with total (Aesthetic Function) was the highest level $(\bar{\chi}=4.66)$ as in term of color and pattern, in term interesting unique and in term of supporting product value were a high level $(\bar{\chi}=4.20)$, safety for usability and easily convenient usability.

\section{Discussion of Research Result}

This research has focused of the creating product process with integration the wisdom of basketwork handicraft and pottery handicraft, searching design method, techniques, approach and production process for achieving in the integrated product as the appliance product according to consumer sampling group demand. This research have discovered that the producer groups have learnt about the method, thinking process, product development, understanding in pattern development, design of the pottery that integrated together with the basketwork should have to know production method process of material that brought to assemble with the basketwork to understand about the limitation condition of production since material preparing process, size of vertical line and horizon line that affected to the strength, figure size of product form, weaving process, forming structure with the vertical line method, weaving on model, weaving in real which using different material pattern, the horizon line for weaving should correspond with the stand line too,

The effect of the exploration result that revealed producers, researcher, student as co-researcher have learnt about the systematic thinking process, the planning and developing of product pattern which using 2 material to assemble together, thinking and working together and get the suggestions as the improvement guideline that conduce to the optimal beautiful product prototype as acceptance by consumer sampling group, especially the optimal pattern of production process which the co-researcher had a new knowledge guideline for further development with various patterns, as the opinion and the satisfaction of consumer sampling group and producers group have realized on the importance of pattern development from the investigation process that have been the opinions and requirement of a social group during the period time not forever owing to consumer group demand will change on social value at current, with conditions all the time, therefore producers group would be awareness of the social changing all the time, being observed demand of target consumer, thence managed to development at intervals and continuously.

\section{Suggestions}

These researches have the suggestion for conducting the result of research to use for benefits and the suggestion for the next research have the consideration as: Suggestion for conducting result to use for benefits

1. Pattern of earthenware edge distance should consider about size of material line that brought to assemble for weaving together in order to specify a hole size for binding and a thickness of optimal vertical line with perfectly.

2. Pattern of decoration commodity product should consider the usefulness of weight supporting, easy for convenient moving, and should not design of basketwork be able support a weight

3. Production should consider about the pattern with taking off to assemble the model with convenient.

4. Consideration of trend design, trend color, and trend of home decoration with each year for applying together that getting worked better.

\section{Suggestion for the Next Research}

1. The evaluation of home decoration items product with various patterns by conducting the pottery integrated with the basketwork, asking for the opinion that would be? For market testing of the possibility of developing with quality as product for exportation.

2. There should study of development of bringing the pottery integrated together with basketwork for applying with other furniture product.

3. For further study of bringing the process pattern or unique from this study conduce for further development with other materials such as wood, steel, leather, other fiber etc.

\section{Acknowledgments}

This research was supported by Suan Sunandha Rajabhat University.

\section{References}

Bunwong, N. (2002). Principal of Design. Bangkok: Chulalongkorn University Printing House Press.

Chammaric, S. (1986). Thailand Political and Constitutional Development. Bangkok: Thammasart University.

Chansoon, S. (1991). Folk Wisdom. In the National Culture Committee, the Office of. 
Chareonrath, O. (2003). Sufficiency Economy under Social changes of Thailand. Bangkok: Pimdee Press.

Gunnasuth, P. (1999). Statistic for Botanical Research. Bangkok: Chulalongkorn University Printing House.

Leesakul, W. (1989). The weaving Stuff in Thailand. Bangkok: Odeon Store Press.

Leesakul, W. (2003). Folk Art. Bangkok: Amarin Printing.

Office of the Special Coordinator for the project due to the initiative. (2009). [Online].

Pungthein, T. (2000). Statistic and Research. Bangkok: Sootpaisan. Odeon Store Press.

Panthavisit, S. (2000). The sufficiency and the survival of Thai rural community: The northeast. Bangkok: Report Research.

Sangpairoj, S. (2001). The satisfaction of consumer towards wickerwork Craft from vetiver leaves. Bangkok: Rankhamhaeng University. Retrieved from http://www.wt.ac.th/ mayuree /e-book/batik1.htm

Sroinakapong, S. (1996). Using of local knowledge to enhance teaching and learning in schools. Course of development content.

Sudsung, N. (2000). Industrial Design and Product Development Industry. Bangkok: Textbooks and document Faculty of Industrial Education and Technology King Mongkut's Institute of Technology Ladkrabang.

Sudsung, N. (2004). The Industrial Product Design Research. Bangkok: Odeon Store.

Suksod, T. (2001). Industrial Product Design. Bangkok: Odeon Store Press.

The Community Development Office of Phayao province. (2009). Retrieved from http://phayaofocus.com /home/index.php?option $=$ com_content\&task $=$ view\&id $=125 \&$ Itemid $=48$.

Thepsitha, S. (2007). An economically self-sufficient Community, and the concept of sufficiency economy philosophy in the context of religion and culture. Bangkok.

Thussanapirom, S. (n. d.). A study of technique of product production from vetiver grass. Promotion of industrial production at the household level. The industrial development in the family Industrial Development Bureau, family and craft. Department of Industrial Promotion.

Vejchacheewa, A. (2009). Retrieved from http://www.pm.go.th/blog/3233

Viratchanipawan, V. (2008). Administration of Management guidelines for integrity and sufficiency economy. Bangkok: Process.

Wasee, P. (1991). Cultural and Development. Bangkok: Chulalongkorn University Printing House.

\section{Copyrights}

Copyright for this article is retained by the author(s), with first publication rights granted to the journal.

This is an open-access article distributed under the terms and conditions of the Creative Commons Attribution license (http://creativecommons.org/licenses/by/4.0/). 